This is a self-archived - parallel published version of this article in the publication archive of the University of Vaasa. It might differ from the original.

\title{
Comprehensive review of the recent advances in industrial and commercial DR
}

Author(s): Shafie-khah, Miadreza; Siano, Pierluigi; Aghaei, Jamshid; Masoum, Mohammad A. S.; Li, Fangxing; Catalão, João P. S.

Title: $\quad$ Comprehensive review of the recent advances in industrial and commercial DR

Year: $\quad 2019$

Version: Accepted manuscript

Copyright C2019 Personal use of this material is permitted. Permission from IEEE must be obtained for all other uses, in any current or future media, including reprinting/republishing this material for advertising or promotional purposes, creating new collective works, for resale or redistribution to servers or lists, or reuse of any copyrighted component of this work in other works.

\section{Please cite the original version:}

Shafie-khah, M., Siano, P., Aghaei, J., Masoum, M.A.S., Li, F., \& Catalão, J.P.S., (2019). Comprehensive review of the recent advances in industrial and commercial DR. IEEE transactions on industrial informatics 15(7), 3757-3771. https://doi.org/10.1109/TII.2019.2909276 


\title{
Comprehensive Review of the Recent Advances in Industrial and Commercial DR
}

\author{
Miadreza Shafie-khah, Senior Member, IEEE, Pierluigi Siano, Senior Member, IEEE, Jamshid Aghaei, Senior Member, IEEE, \\ Mohammad A. S. Masoum, Senior Member, IEEE, Fangxing Li, Fellow, IEEE, and João P. S. Catalão, Senior Member, IEEE
}

\begin{abstract}
Industrial and commercial electricity customers have significant potential in providing flexibility for power systems through diverse Demand Response (DR) programs. However, the industrial and commercial potential of DR is not yet completely understood, especially regarding the emerging and advanced technologies associated with the smart grid. Advances in smart meter technology that allow monitoring and controlling responsive loads in real-time will also be key enablers of DR potential. It can be more complex to implement DR for industrial loads if compared to residential loads mainly due to the reliability management that is more vital for industrial plants. Hence, this paper aims at providing a comprehensive review of the most recent advances on industrial and commercial DR. On this basis, this survey firstly presents the potential and technologies of DR in industrial and commercial sectors. Then, the existing models of DR in the mentioned sectors are presented. The presence of industrial and commercial DR in electricity markets is also investigated. Finally, the main positive and beneficial aspects, as well as challenges and barriers of industrial and commercial DR, are investigated.
\end{abstract}

Index terms-Barriers, benefits, commercial demand response, industrial demand response, potentials, market, technologies.

\section{NOMENCLATURE}

\section{Abbreviation}

ATC

BAS

CHP

DA

DER

DG

DOPF

DR

DRX

DSM

EENS

EMS

EV

G2V

GenCo

GOOSE

GSSE

HVAC
Available transmission capacity

Building automation systems

Combined heat and power

Day-ahead

Distributed energy resource

Distributed generation

Dynamic optimal power flow

Demand response

Demand response exchange

Demand-side management

Expected energy not supplied

Energy management systems

Electric vehicle

Grid-to-vehicle

Generation company

Global object oriented substation event

Generic substation status event

Heating, ventilation, and air conditioning
J.P.S. Catalão acknowledges the support by FEDER funds through COMPETE 2020 and by Portuguese funds through FCT, under SAICT-PAC/0004/2015 (POCI-010145-FEDER-016434), 02/SAICT/2017 (POCI-01-0145-FEDER-029803) and UID/EEA/50014/2019 (POCI-01-0145-FEDER-006961).

M. Shafie-khah is with the School of Technology and Innovations, University of Vaasa, 65200 Vaasa, Finland (e-mail: miadreza@gmail.com)

P. Siano is with the University of Salerno, Salerno, Italy (e-mail: psiano@unisa.it).

J. Aghaei is with the Department of Electrical and Electronics Engineering, Shiraz University of Technology, Shiraz, Iran, also with the Department of Electric Power Engineering, Norwegian University of Science and Technology (NTNU), Trondheim NO-7491, Norway (e-mail: aghaei@sutech.ac.ir ).

M.A.S. Masoum is with the Department of Engineering, Utah Valley University, Orem, Utah, USA (e-mail: mmasoum@uvu.edu).

F. Li is with the Department of EECS, The University of Tennessee, Knoxville, TN 37996 USA (email: fli6@utk.edu).

J.P.S. Catalão is with the Faculty of Engineering of the University of Porto (FEUP) and INESC TEC, Porto 4200-465, Portugal (e-mail: catalao@fe.up.pt).

$\begin{array}{ll}\text { ICT } & \text { Information and communication technology } \\ \text { IED } & \text { Intelligent electronic device } \\ \text { IGDT } & \text { Information gap decision theory } \\ \text { IMG } & \text { Industrial microgrids } \\ \text { IoT } & \text { Internet of things } \\ \text { ISO } & \text { Independent system operator } \\ \text { LMP } & \text { Locational marginal price } \\ \text { LSE } & \text { Load serving entity } \\ \text { NSGA II } & \text { Non-dominated sorting genetic algorithm } \\ \text { QoS } & \text { Quality of service } \\ \text { RTP } & \text { Real-time pricing } \\ \text { SMV } & \text { Sampled measured values } \\ \text { SOC } & \text { State-of-charge } \\ \text { V2G } & \text { Vehicle-to-grid } \\ \text { VPP } & \text { Virtual power plant }\end{array}$

\section{INTRODUCTION}

Industrial and commercial sectors include a major part of the energy consumption that accounts for more than $60 \%$ of the total energy use around the world [1]. Demand Response (DR) has been widely employed in these two sectors since 1970, but nowadays it has been transforming thanks to technology developments and market improvements [2]. Particularly, wholesale energy and ancillary services markets can incentivize the participation of DR in the markets [3]. Moreover, advances in smart devices and telecommunication technologies can enable faster and better management of DR as an emerging resource, while facilitating the participation of smaller entities [4]. On this basis, DR management has been widely addressed in the literature, and participation of DR has been investigated in terms of potential, technologies, market, and modeling. The existing literature can be categorized into three major groups.

The first category of the existing literature investigates the impact of DR, especially in commercial and industrial sectors due to the high share of these sectors on air pollution. In [2], the impact of highly aggregated DR and large-scale DR implementation in different sectors is characterized by emissions over an extended planning horizon. This study revealed that although in the shortterm, increasing the DR implementation could increase air emission due to shifting the demand from the low-carbon-intensive peak capacity to the high-carbon-intensive non-peak capacity, in the longterm, DR deployment could reduce the air emission as well as expansion planning costs.

In the second category, programs, approaches and various markets are discussed. In [5], the potential of ancillary services on industrial DR has been studied. To this end, industrial loads' characteristics have been analyzed, and their potential for taking part in different types of ancillary services has been investigated. The authors of [5] have classified different types of industries regarding DR potential in terms of economic and technical aspects and have presented the barriers to DR programs in the industries. Moreover, programs, issues, approaches and future extensions of DR have been surveyed in [6]. To do so, the means of the electricity utility to incentivize the customers to re-schedule their consumption pattern have been introduced. Moreover, the mathematical models and problems have 
been gathered and compared. Ref. [7] surveyed several DR programs, based on incentivizing the consumers to take part in the programs. To this end, the DR schemes have been classified in terms of control mechanisms. Furthermore, optimization models for the optimal control of the DR programs have been categorized according to the optimization objective.

The third category of the existing surveys devoted to challenges, benefits, and barriers of DR. For example, in [8] and [9], the uncertainty and other challenges for DR utilization have been reported, while the benefits of DR as a source have been presented. Based on these reports, the main challenge is how to establish a reliable control strategy and market framework for optimal deploying the DR, particularly because of the lack of experience in this context. Ref. [10] focused on the DR barriers, surveyed the barriers of regulatory, and market design to the realization of DR in the distribution systems from the European perspective. Ref. [11] went a step further and categorized DR barriers based on 'sociotechno-economic' features into fundamental and secondary barriers. Fundamental barriers are related to economic, social and technological limitations, while secondary barriers are mostly related to political issues, market designs, and electrical network limits.

According to the literature, most of the surveys studied the general $\mathrm{DR}$, specific berries and challenges of industrial and commercial have not been well addressed, and there is still a need to investigate the challenges according to recent advances in industrial and commercial DR. To this end, this paper classifies the previous literature into four groups; a) potential and technologies of DR in industrial and commercial sectors, b) existing models of DR in industrial and commercial sectors, c) the role of electricity markets in industrial and commercial DR, and d) benefits and barriers of industrial and commercial DR.

The rest of this paper is organized as follows. In Section II, potential and technologies of industrial and commercial DR sectors are presented. Section III is dedicated to a comparison between different models of industrial and commercial DR. In Section IV, commercial and industrial DR in electricity markets are investigated. Section V presents the benefits of industrial and commercial DR. In Section VI, barriers to industrial and commercial DR are listed. Finally, Section VII concludes the paper.

\section{PARTICIPATION OF COMMERCIAL AND INDUSTRIAL SECTORS IN DEMAND RESPONSE}

Demand-Side Management (DSM) aims to change the patterns of end-user electricity consumption by improving energy efficiency and optimal allocation of power [1]. DR is a DSM solution performed by motivating residential, commercial and industrial customers to reduce or shift their demand at a specific time and duration. This can be carried out by using on-site generations or by reducing the consumption level to comply with a DR event [12]. The potential of these sectors and the impact of technologies on industrial and commercial DR are presented as follows.

\section{A. Potentials of commercial and industrial $D R$}

Participation of commercial and industrial sectors in DR can provide several potentials in terms of interaction with renewable sources, features of industrial demand, as well as privacy and security improvement. These potentials of commercial and industrial DR are discussed as follows.

\section{Renewable Sources Interaction}

In the traditional centralized power systems, the generation is configured to follow the demand of consumers while in the new smart grid configurations day-ahead schedule of distributed generations (DGs) are developed by predicting the consumers' load profile [13]. Therefore, consumers may choose their energy sources among conventional and renewable DGs with more freedom [14]. In addition, microgrids are developed as self-sustaining systems, integrating DGs and energy storages as well as real-time control and energy transaction [15]. However, with the renewable DGs and microgrid, predicting consumer demand and implementation of DR programs are more difficult. The consumer demand is expected to be coordinated with the electricity generation. This is the main objective of DR management that aims at shaping the load profile for balancing energy demand and supply considering the stochastic nature of renewable resources [16].

The industrial sectors consist of industrial factories, facilities and plants with electric loads. Some factories require heat for their production processes that is obtained from combined heat and power (CHP) systems or the boilers. The formation of the developing industrial microgrids (IMGs) is due to the corporation of a few factories with distributed energy resources (DERs). The industrial sector consumers (factories and IMGs) rely on DERs such as CHP systems and renewable energy resources as well as energy storage systems. The new generations of loads and storages are grid-tovehicle $(\mathrm{G} 2 \mathrm{~V})$ charging and vehicle-to-grid (V2G) discharging of plug-in electric vehicles, respectively. However, DR has received limited attention in the developing IMGs within the industrial sectors due to special requirements of industrial loads and their interactions with renewable resources, energy storage and EVs [17]. In the industrial sectors, renewable wind and PV DGs are being accepted as suitable alternatives to the conventional distributed generators due to environmental concerns. Although renewable energy resources currently represent a low percentage of global electricity production, their applications in industrial sectors are expected to grow rapidly. This is particularly for distributed PV generators since the peaks of most industrial loads usually coincide with the maximum output of the PV modules. In fact, most industrial factories and IMGs can install PV plants and utilize clean energy to reduce the cost associated with the operation of their thermal units. According to [18], PV generation as a sustainable energy solution should provide up to $12 \%$ of electricity demand by $2020,20 \%$ in 2030 and $30 \%$ in 2050 . Consequently, in industrial sections where the peak of electricity demand usually occurs during the daytime, the application of PV generation systems can have an important role in the IMG operation within the next few years.

The interactions of distributed generators including renewable resources are often coupled with energy storages such as batteries. This will allow IMGs to store the excess generated energy in storage units during off-peak hours and to return it to the system at appropriate times. This arrangement can moderately mitigate the stochastic nature of renewables such as PV production in real time [19] and increase the factory/MG profit by selling the stored energy during peak hours [20].

\section{Specific Features of the Industrial Sector}

The implementation of DR for industrial consumers is more dif• cult than residential consumers and commercial buildings, since it requires considerations of a few additional factors such as [21]:

- The flow of other resources such as raw materials, intermediate materials, water, and gas.

- Real-time operation of factories.

- The mismatch between energy supply and demand of industrial facilities.

- Significant energy generation from the process itself.

The industrial sectors mainly serve consumers that require high energy with typical peak loads of hundreds of MWs at high voltage levels such as plants, factories, IMGs. 
Industrial consumers have a number of unique requirements that distinguished them from residential and commercial consumers [7]:

- Power and voltage ef• ciencies are extremely vital.

- Most manufacturing processes have critical temporal dependencies that may require precise scheduled with high timing precision. In most cases, it is essential to have millisecond scale monitoring and control of the plant.

- Security issues are very important since the access to load profiles/shapes information is highly con•dential and competition-sensitive.

- Therefore, many industrial facilities are familiar with DR programs such as the application of dynamic pricing models.

- However, intelligent DR methods may further increase the reliability of the industrial system and the economic ef• ciency of the electricity infrastructure [22].

\section{Privacy and Security}

The consumer privacy protection and security are critical in enabling DR management. The decentralized DR programs assure scalability while also providing consumer privacy protection, by preventing central authorities from collecting information for decision-making [7]. Future research directions should include security and privacy issues that arise from the management of metering data with private information and activities or choices of the consumers.

The security issues are particularly important in the industry since the information of load profiles and load shapes are highly con-dential and competition-sensitive as they may indicate the types, times and durations of equipment and loads. Security of DR is vital for the innocuous operation of the industrial equipment. Hence, for many years various industrial facilities have been participating in actions that are very familiar to the smart grid applications, frequently through the application of dynamic pricing models [7].

Application of intelligent DR methods can increase the security of information as well as the reliability and economics of the industrial system [22].

Several security issues may compromise the effectiveness of a DR scheme such tampering of pricing information that can result in - nancial and legal problems and malware and viruses attacks that may cause severe damage to the power delivery system. It is therefore essential to implement secured DR programs that protect the private data of consumers, avert unauthorized access and provide authentication, authorization and auditability to the communication infrastructure. For a more comprehensive study on the communication requirements, challenges and solutions for DR, the interested reader may refer to [7], [23].

\section{B. Technologies}

Various types of technology can affect the industrial and commercial DR. The main influential technologies are presented as follows.

\section{Combined Heat and Power}

CHP systems such as gas turbine, natural gas engine and microturbines facilitate energy-efficient power generation in IMGs by capturing the waste heat [17], [24]. These systems maintain the heat acquired from power generation units and utilize it for domestic and industrial heating purposes [17]. The generated heat (at moderate temperatures of $100^{\circ} \mathrm{C}$ to $180^{\circ} \mathrm{C}$ ) can also be used in absorption chillers for cooling [25]. Among various types of CHP systems, gas turbine, natural gas engine and microturbines have more applications in the industrial sectors [24]. CHPs are dispatchable systems with low investment costs that can continuously generate energy for hundreds of hours [17], [25]. They have appealing operational flexibility with fast start up and shut down times as well as high ramp rates [26].

\section{Storage and Electric Vehicles (EVs)}

The DR in the industrial sectors involves dynamic optimal power flow (DOPF) formulation considering factories constraints and IMG security as well as time and energy related charging/discharging constraints associated with the storage units such as batteries and EVs. The commercial sectors also include storage systems such as batteries and EVs. In addition, the effect of renewable generation systems coupled with storages on DR and generation scheduling must be considered. The main challenge for the DR provider in the industrial and commercial sectors is to provide an effective and efficient baseline to encourage the consumers/factories to adopt demand control without producing substantial problems in the price formation in wholesale markets [27].

Reference [28] has investigated and modeled the impacts of EVs on distribution networks. An application of DR that relies on storage is the response management in G2V and V2G systems [29]. Some of the large factories, industrial parks and IMGs within the industrial sectors have heavy and large vehicles such as picker trucks, lift trucks, bucket trucks and delivery trucks that can be replaced with EVs [28]. Reference [29] investigates an incentivized auction based two-level group-selling approach for V2G DR management to reduce the system cost and maintain the system stability. The first auction level is formed between the grouped EVs and the aggregator. The second level is between the aggregators and the power grid.

The V2G technology enables two-way communications and bidirectional energy flow between EVs and grid with the aggregator acting as the agent for the battery management [13].

Dynamic pricing encourages the EV charging to consume the redundant energy from the grid while during peak load hours; EV users perform discharging to feed energy back to the grid for energy arbitrage. The authentication schemes based on EVs guarantee the security of $\mathrm{V} 2 \mathrm{G}$ communications [30]. With the developments of the internet of vehicle [31] and vehicular cloud [32], the V2G technology enables EVs to achieve flexible DR management in real time.

Different EV management approaches have been associated with DR management services. The EV control strategy associated with DR can perform off-peak charging [28], change behaviors of EV users based on dynamic pricing [33], utilize the electricity generation from wind and solar power [34], consider battery stateof-charge (SOC) and provide grid frequency regulation [35]. In addition, other factors such as EV user profit [36], the costs of grid [33], and fairness [37] have been used in the literature to improve the performance DR.

For the integration of V2G systems in DR programs, a fundamental understanding of EV demand and EV mobility is essential since these factors will influence the availability and the capacity of vehicle batteries. Most studies consider random charging demands by assuming arrived EVs have random initial SOCs [34], [35]. Different approaches are used to model EV mobility and the arrival process including Gaussian distribution, Poisson process [38], and Markov chain [36].

Most studies ignore EV mobility across different areas by limiting it within a single geographic area or an isolated node. While in real scenarios, EVs can serve as mobile units and transport energy from one area to another. Reference [39] explores electricity transmission and distribution by using electric buses that travel among stations regularly and transport energy from renewable sources to consumers. Reference [40] analyses the energy routing problem to reduce the total hops of energy and the blocking of energy routes.

\section{Sensors and Metering Facilities}


Proper sensors and metering facilities are essential in preventing and resolving industrial and commercial consumers' issues related to DR programs. For example, Real-Time Pricing (RTP) schemes require the energy provider to be in continuous and real-time communication with the customers. This is not an attractive arrangement from the user perspective [7].

In addition, the effectiveness of RTP is affected by the mass - ow of data exchanged between the energy provider and the EMCs, as well as the efficiency and complexity of smart metering. An alternative is to implement Day-Ahead RTP (DA-RTP) based solutions; the customers are billed for their consumption based on the next day predicted real-time prices that are announced beforehand [41]. Another alternative is to offer financial incentives to retail customers to invest in smart metering infrastructure. This will provide the opportunity to switch from a $\cdot$ xed retail rate to more dynamic pricing [42].

\section{Distributed Generators Interactions}

Many utilities have started using on-site DERs to improve the reliability of the plant while also reducing the operational costs. The DER units are used to shield the plant from the unexpected loss of service and to mitigate power quality issues originated on the utility side [43]. In most utilities, DERs are some types of DG units, renewable resources or energy storage systems. The DERs are either dispatchable units such as diesel engines that can follow generation set-point commands, or non-dispatchable units such as solar and small-scale wind turbines that typically operate based on maximum power point tracking [43].

\section{Communication Infrastructures}

For the implementation of DR programs, it is essential to have an effective communication infrastructure that provides connectivity to different industrial systems, devices and applications [7]. For example, most organizations such as power supply utilities and independent system operators use centralized control approaches to implement DR programs. Each organization needs to collect the information on all its customers' supply and consumption to determine appropriate prices and incentives [44]. This leads to heavy burdens of communication particularly for organizations with a huge number of customers.

The general communication requirement is a two-way flow of information between the entities participating in the DR program. However, from the network point of view, there are other important operational requirements for the effective and reliable communications between various elements including quality of service, interoperability, scalability, flexibility, security and compatibility with IEC 61850 [7], [45].

Quality of Service (QoS):

The provision of QoS guarantees that as the number of the DR applications, organizations and customers increase, the bidirectional communication infrastructure will be able to provide sufficient bandwidth for reliable transport of the controlling messages with minimum failure rates and latencies. For example, the sensing and metering technology used for real-time pricing requires latency values of a few milliseconds while the bandwidth requirements of DR programs depends on the communication frequency between the organizations and consumers and is a few kilobits per second per consumer [46].

Interoperability:

The provision of interoperability through open standards guarantees that the overall communication system is insensitive to changes or modifications in any one of its underlying components. While the cooperation of different systems is vital in DR programs, there can be an interoperability problem due to different interpretations of the standard by manufacturers, as well as different protocol and data model disparities among organizations and customers. To overcome the problem, the adoption of standards across the communication infrastructure is essential [47]. Such that all equipment properly interoperate and correctly interpret the messages and exchanged data [45]. This can be done by adding interoperability feature to DR management system by considering a layered architecture that ensures high flexibility, together with extensibility and composability [48].

Scalability and Flexibility:

The provision of scalability through the evolutionary implementation of a highly scalable communication infrastructure on a broader scale guarantees the participation of a large number of consumers as well as the accommodation of a large number of devices and services [7]. On the other hand, the provision of flexibility guarantees multiple redundant alternate routes for the data flows and support of the mobility feature for the end devices [7], [46]. The consideration of cloud-based architectures for DR implementation is a very effective solution for the scalable and flexible communication between organizations and the consumers [49].

Security:

The provision of network security provides the means to maintain data integrity, confidentiality and authentication, while facilitating non-repudiation [50]. Security issues can compromise the performance and effectiveness of DR programs. For example, tampering of pricing information may trigger financial and legal problems. Therefore, DR programs need to protect the private data of consumers, avert unauthorized access and provide authentication, authorization, auditability and trust components to the communication infrastructure [23].

\section{Compatibility with IEC 61850:}

Fast and secure communication plays a critical role in the real-time implementation of DR programs. This can be done through the engagement of IEC 61850 standard, which is a set of international standards, originally designed for substation applications to facilitate communications among different intelligent electronic devices (IEDs) and allow interoperability between devices from different manufacturers [51]. IEC 61850 can be used to achieve interoperability in MGs by providing standardized communication and control interfaces among the DER devices. Key features of IEC 61850 are using standardized data names and virtualized models (for logical devices, logical node, etc.) as well as providing selfdescribing devices, standardized configuration language and highlevel services such as Global Object Oriented Substation Event (GOOSE), Generic Substation Status Event (GSSE), Sampled Measured Values (SMV), etc. Major benefits of IEC 61850 are eliminating procurement ambiguity and enabling new capabilities such as wide area protection schemes and sharing more device data, as well as lower installation, transducer, commissioning, equipment migration, extension and integration costs [52]. References [7], [23] provide comprehensive information on DR communication requirements and solutions.

\section{MODELING THE COMMERCIAL AND INDUSTRIAL DEMAND RESPONSE}

Section II indicates that commercial and industrial loads have considerable potential for peak load reduction. From the customer's aspect, the purpose of participating DR is to minimize their electricity bill. A series of constraints should be considered because of the load electrical characteristics and requirement of comfort level. In this section, the business models of commercial and industrial demand are briefly introduced. Due to space limits, the objective functions and constraints only list the most common information aiming at maximizing the revenue or profit of the commercial or industrial customer, while some other constraints and models for complex DR programs are ignored. For instance, DR 
programs involving multiple players using multiple optimization layers can be modeled as typical bi-level optimization problems as shown in [53] involving a utility between consumers and ISOs.

\section{A. Commercial demand response}

The main commercial loads for DR are electric vehicle and heat pumps [54]. Next, their models will be elaborated in detail.

\section{Electric Vehicle}

There are varieties of studies on the optimal scheduling of EV charging under dynamic electricity pricing. From the perspective of EV parking station or aggregator, the EVs can be classified as commercial loads. The aggregators usually attempt to maximize their profit while satisfying EV owners' charging needs. The profit is the summation of each EV's electricity bill.

One of the constraints of the presented models in the literature is the energy balance in the EV battery, including charging losses, and the energy consumption for driving purposes. Another constraint corresponds to the limits of the battery's SOC ratings. The limit of the battery charging power, which depends on the energy capacity of the battery and the grid connection states, is also considered in the literature. EV is assumed being connected to the grid when it stays in the parking lot. Therefore, the nature of optimal EV charging is to regulate the charging statement such that the total electricity bill is minimized [55]. Some other constraints are also considered for different optimization models. However, the mentioned constraints can be inserted into any optimization model as the basis for other relevant research directions [56]. A comparison between EV's optimal scheduling models is presented in Table I.

\section{Electric Heat Pump}

The EHP is widely used in commercial buildings and has great potential for peak load reduction due to its heat inertia characteristics. A typical optimization model of EHP is proposed in [55]. The structure of the considered space heating system is depicted in Fig. 1. The objective function minimizes the total electricity bill of an EHP over 24 hours. The dynamic temperature response of a building can be modeled by a second-order difference equation characterized by lumped parameters whose values depend on the building materials [65].

The building's thermal behavior constraints have been presented in various reports such as [66] by using functions of the lumped parameters. Another constraint is the limits of the electric input and thermal output. In addition, the EHP thermal and electric power capacities are linear functions of outdoor and indoor temperatures, where are formulated according to the EHP technical characteristics. The ratio of the thermal output over the electric input is known as the coefficient of performance [67]. Regarding the heat storage operation, a constraint should represent the thermal energy balance in the storage including energy losses. Moreover, the lower and upper limits of the storage's energy content are considered in the literature [67].

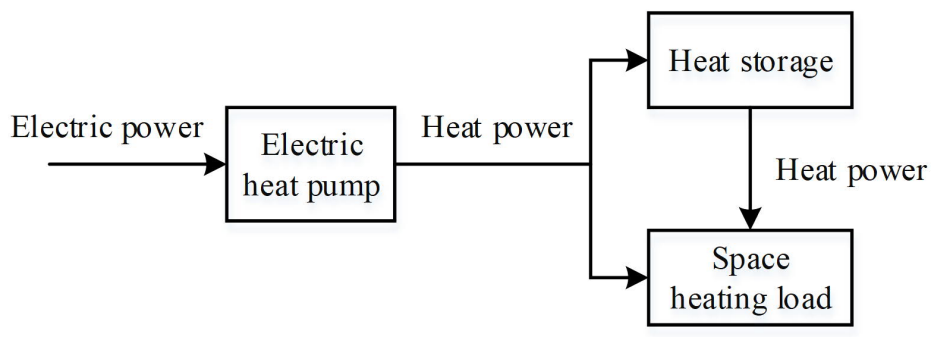

Fig. 1. Structure of considered space heating system [55].

The maximum heat power charging and discharging rates are other constraints of the EHP models. Furthermore, the heat power input of the storage cannot exceed the heat power output of the EHP. Moreover, users' thermal comfort requirements are formulated in the models in terms of the desired indoor temperature at each hour.

To summarize, flexible EHP systems determine the optimal periods for their storage charging based on the combination of prices and indoor/outdoor temperatures [55].

\section{$B$. Industrial demand response}

Some industrial loads have the potential to participate in DR. The major examples include aluminum smelter and steel manufacturing plant. In addition, we assume that the industrial load owners' bidding/offering does not affect the final market clearing prices. This is reasonable as the total power capacity of a factory is still small compared to the power system's total generation capacity [68]. Overall, the industrial load adjusts the scheduling to minimize its net cost, which is the cost of electric energy minus the revenue from spinning reserve provision [68]-[71].

\section{Aluminum Smelting Factory}

Aluminum smelting is an energy-intensive electrolytic process that is widely used to produce aluminum. Reference [52] introduces experiences of an aluminum smelter (called Alcoa Warrick Operation) for DR. The aluminum smelter is able to adjust its power consumption by adjusting tap changers in the rectifier that supply DC electricity to the production lines [69]. In the smelting plant, the electrolytic process takes place in the so-called cell and is enabled by a DC electric current that passes through the cell. A large number of cells, or pots, are connected in series to form a potline.

The total power consumption of a potline can be hundreds of MWs. Typically, there are several potlines in an aluminum smelter. The relation between the production profit and potline power is a nonlinear empirical function. It can be approximated by a piecewise function. Then, the optimal scheduling is a mixed integer linear programming problem. Under the dynamic price, the potlines power can be adjusted by controlling the power consumption in each hour [68].

The basic objective function maximizes the sum of the profit from producing aluminum and the revenues from providing the electricity market with spinning reserve.

\begin{tabular}{|c|c|c|c|c|}
\hline Reference & Point of view & Objective function & Optimization method & Time horizon \\
\hline$[57]$ & Aggregator, EV owners & Max. aggregator's profit & DP & Two-stage \\
\hline [58] & Parking station operator, EV owner & Max. average SOC of all EVs at the next time step & Swarm intelligence & Real-time \\
\hline [59] & Aggregator, EV owners & Max. aggregator's profit, Min. total charging cost & LP & $\begin{array}{l}\text { Day-ahead (static) } \\
\text { Real-time (dynamic) }\end{array}$ \\
\hline$[60]$ & Aggregator & Max. aggregator's revenue & MILP & Real-time \\
\hline$[61]$ & Aggregator & Max. aggregator's profit & FLP & Real-time \\
\hline$[62]$ & Parking station operator, EV owners & $\begin{array}{l}\text { Max. parking lot revenue or Max. total number of } \\
\text { EVs fulfilling charging requirement }\end{array}$ & $\begin{array}{l}\text { LP + first come first } \\
\text { serve }\end{array}$ & Two-stage \\
\hline$[63]$ & Aggregator, EV owners & Min. total charging cost & $\mathrm{DP}$ & Day-ahead \\
\hline [64] & Parking station operator & Max. profit & Stochastic programming & Day-ahead \\
\hline [56] & Parking station operator & $\begin{array}{l}\text { Max. total number of EVs for charging and Min. } \\
\text { charging cost }\end{array}$ & $\begin{array}{l}\text { Modified convex } \\
\text { relaxation method }\end{array}$ & Day-ahead \\
\hline
\end{tabular}


The major constraints are related to the chemical characteristics of an electrolytic tank:

- The maximal capacity of available spinning reserve;

- Minimum energy consumption for every successive $\tau$ hours to sustain the tank temperature; and

- Daily minimum and maximum energy consumption. According to experimental studies, the demand of electrolysis process can decrease up to $25 \%$ for four hours before an undesirable interruption occur [52]. The capacity of the available spinning reserve is upper bounded by the difference between the current loading level and minimum loading level of a potline. Furthermore, the payment structures for spinning reserve are different at different electricity markets. More items should be included, if the aluminum smelter participates in other markets (e.g., both DA and spinning reserve markets) [69].

\section{Steel Manufacturing Plant}

Steel manufacturing plants consume large amounts of electricity as well, and their electricity bills account for a remarkable percentage of their total operation cost. Therefore, steel plant owners are motivated to participate in DR programs. A plant can adjust its power consumption by controlling the service transformer tap changer. There are four stages in the steel production process: electric arc furnace, argon oxygen decarburization, ladle furnace, and continuous caster. Therefore, the optimization model should consider not only each stage itself, but also the transformation between stages [71]. According to [72], the objective function minimizes the cost of the steel production minus the revenues from providing the electricity market with spinning reserve.

The major constraints are related to the steel production process:

- Energy balance and the maximal amount of available spinning reserve; and

- Production limit: each set of metal is processed exactly once at each stage.

If compared with other DR, the scheduling time step of the steel plant is typically 15 minutes instead of 1 hour. According to [72], the method brings up to $12 \%$ savings in high capacity operations and up to $52 \%$ in low capacity ones.

\section{Cement plant}

Cement plants consume a high amount of electricity and have a significant part of the industrial sector. For example, cement plants have more than $8 \%$ of the industrial consumption share in China where the biggest producer of the product is so that more than $57 \%$ of the world's cement is produced [73].

Participation of cement plants in DR programs is associated with price-based DR programs, especially RTP. On this basis, in the models of cement plants that participate in the DR programs dynamic prices are considered. The model optimizes the cement production in a way the original throughput is ensured, while the electricity cost is at the lowest level even though any changes in the electricity price happen. To this end, the objective function minimizes the electricity cost that equals the sum of the hourly load of the cement plant multiplied by the hourly electricity price.

In order to guarantee the original throughput of the cement plant, a constraint is considered to ensure the expected electricity consumption of each process is a fixed value. Moreover, another constraint of the semi-shift process is required in which the load can be only shifted at a given time slot [73].

It should be noted that loads of cement plants could be categorized into three types of load, namely, non-shift, semi-shift, and full-shift. In the literature, cement grinding and packaging are considered full- shift processes. Kiln, preheating and coal grinding are non-shift processes, while crushing can be considered the semi-shift process.

\section{Pulp and paper mill}

The pulp and paper mills are also one of the significant consumers in the industrial sector. For example, a huge amount of electricity is used for separating fibers from lignin and for making these fibers soft and suitable for starting the papermaking process. If the thermomechanical pulping lines of the pulp and paper mills have higher capacity than the paper machines, it is possible that the process of pulp production is operated in a way to consider dynamic electricity prices [74]. This can be the capability of this industry to participate in the price-based DR programs and consequently to provide a capability for minimizing its total electricity cost. On this basis, the objective function of the pulp and paper mills minimizes the electricity costs, considering the utilization of storage systems according to the expected electricity prices and the scheduled production.

Various constraints should be considered to guarantee the original throughput. One of the main constraints that should be met is the total steam demand. In addition, the capacity of other sources of steam is limited. Moreover, each source of steam has a different cost that should be taken into account. Another important constraint is the planned production of the paper machines. Furthermore, refiner lines cannot surpass either the maximum or the minimum productions.

\section{COMMERCIAL AND INDUSTRIAL DEMAND RESPONSE IN ELECTRICITY MARKETS}

In recent years, DR participation in electricity markets has drawn lots of attention. Many papers have been published in this field. A summary of these works is shown in Table II. In addition, Fig. 2 shows how the information is classified. In the following subsections, each classification has been surveyed.

\section{A. DR in different electricity markets}

The impact of DR on the wholesale market, retail market and ancillary service markets has been surveyed in the following.

\section{DR in the Retail market}

Song et al. [90] aimed to determine the day-ahead market bidding strategies for retailers with flexible demands to maximize the shortterm profit. It proposed a short-term planning framework to forecast the load under dynamic tariffs and construct bidding curves. Stochastic programming is applied to manage the uncertainties of spot price, regulating price, consumption behaviors and responsiveness to dynamic tariffs.

In 2011, Nguyen et al. [81] propose a new concept, demand response exchange (DRX), in which DR is treated as a public good to be exchanged between DR buyers and DR sellers. DRX can be considered as an implicit market in which DR is separately traded through a virtual pool. Thimmapuram et al. [85] explored the impact of consumers' price elasticity of demand on the performance of the electricity market using electricity market complex adaptive system. It indicated while the impact depends on the price level at which consumers' exhibit price responsiveness; price-elastic consumers could benefit by a reduction in energy usages and prices and significantly reduce congestion charges and, potentially, reduce the market power of generation companies (GenCos). 
TABLE II. SUMMARY OF THE COMMERCIAL AND INDUSTRIAL DR PAPERS IN ELECTRICITY MARKETS

\begin{tabular}{|c|c|c|c|c|c|c|c|c|}
\hline \multicolumn{9}{|c|}{ MARKE } \\
\hline $\begin{array}{l}\vec{\pi} \\
\stackrel{0}{0} \\
\overrightarrow{0} \\
\overrightarrow{0} \\
\overrightarrow{0}\end{array}$ & 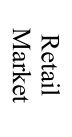 & 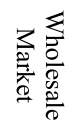 & 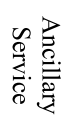 & 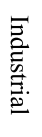 & 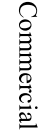 & 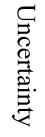 & 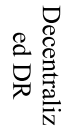 & 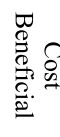 \\
\hline$[75]$ & $x$ & $x$ & $\checkmark$ & $\checkmark$ & $\checkmark$ & $x$ & $x$ & $x$ \\
\hline$[76]$ & $x$ & $\checkmark$ & $x$ & $\checkmark$ & $\checkmark$ & $x$ & $\checkmark$ & $\checkmark$ \\
\hline $\begin{array}{l}777] \\
\end{array}$ & $x$ & $\checkmark$ & $x$ & $\checkmark$ & $\checkmark$ & $x$ & $x$ & $\checkmark$ \\
\hline$[78]$ & $x$ & $x$ & $\checkmark$ & $\checkmark$ & $\checkmark$ & $x$ & $x$ & $x$ \\
\hline [79] & $x$ & $\checkmark$ & $x$ & $x$ & $\checkmark$ & $x$ & $\checkmark$ & $x$ \\
\hline$[80]$ & $x$ & $\checkmark$ & $x$ & $\checkmark$ & $\checkmark$ & $x$ & $x$ & $\checkmark$ \\
\hline $\begin{array}{l}{[81]} \\
\end{array}$ & $x$ & $x$ & $\checkmark$ & $\checkmark$ & $\checkmark$ & $x$ & $x$ & $x$ \\
\hline$[82]$ & $\checkmark$ & $x$ & $x$ & $x$ & $\checkmark$ & $x$ & $\checkmark$ & $x$ \\
\hline$[83]$ & $\checkmark$ & $x$ & $x$ & $\checkmark$ & $\checkmark$ & $x$ & $\checkmark$ & $\checkmark$ \\
\hline [55] & $\checkmark$ & $x$ & $x$ & $x$ & $\checkmark$ & $x$ & $\checkmark$ & $\checkmark$ \\
\hline [84] & $x$ & $\checkmark$ & $x$ & $\checkmark$ & $\checkmark$ & $x$ & $\checkmark$ & $x$ \\
\hline [85] & $\checkmark$ & $x$ & $x$ & $\checkmark$ & $\checkmark$ & $x$ & $\checkmark$ & $\checkmark$ \\
\hline$[86]$ & $x$ & $x$ & $\checkmark$ & $\checkmark$ & $\checkmark$ & $\checkmark$ & $x$ & $\checkmark$ \\
\hline \begin{tabular}{|l}
{$[87]$} \\
\end{tabular} & $x$ & $\checkmark$ & $x$ & $\checkmark$ & $\checkmark$ & $x$ & $\checkmark$ & $x$ \\
\hline$[88]$ & $x$ & $\checkmark$ & $x$ & $\sqrt{2}$ & $\checkmark$ & $\checkmark$ & $\checkmark$ & $\checkmark$ \\
\hline [89] & $\checkmark$ & $\checkmark$ & $x$ & $\checkmark$ & $\checkmark$ & $\checkmark$ & $x$ & $x$ \\
\hline$[72]$ & $\checkmark$ & $x$ & $\checkmark$ & $\checkmark$ & $x$ & $x$ & $\checkmark$ & $\checkmark$ \\
\hline [90] & $\checkmark$ & $x$ & $x$ & $x$ & $\checkmark$ & $\checkmark$ & $\checkmark$ & $\checkmark$ \\
\hline
\end{tabular}

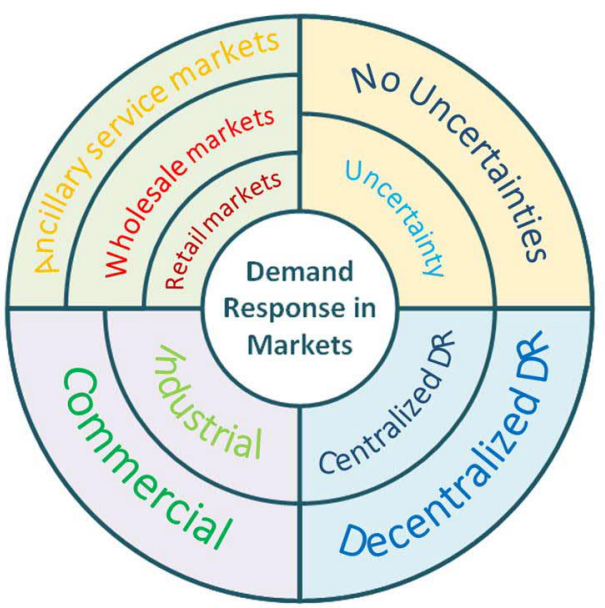

Fig. 2. DR in markets classification

\section{DR in the wholesale market}

Parvania et al. [84] presented an optimization framework for the DR aggregation in the wholesale electricity markets. The aggregation of DR contracts is considered in the proposed price-based selfscheduling optimization model to determine optimal DR schedules for participants in the day-ahead energy markets. In addition, Parvania et al. [87] presented a hierarchical DR bidding framework in the day-ahead energy market that integrates customer DR preferences and characteristics in the Independent System Operator (ISO)'s market clearing process. The hourly load reduction strategies include load shifting and curtailment and the use of onsite generation and energy storage systems. The results indicate that the explicit modeling of customer DR would provide ISOs with flexible options to schedule available energy resources in the DA wholesale energy markets.

\section{DR in the Ancillary service market}

Improvements in technology and other areas enabled DR to participate in markets. DR is used for various ancillary purposes like providing reserve markets ([72], [81]), preventing congestion ([78], [86]), etc. In 2005, Paulson published a paper that explains how demand resources are being integrated into the PJM ancillary service markets [75]. Shayesteh et al. [78] used DR in congestion management. The aim is to avoid transmission congestion in a leastcost manner. Aghaei and Alizadeh [86] investigated ancillary service DR programs in an $n-k$ contingency constrained unit commitment problem. To implement the program, DR providers offer their bid prices to ISOs to compete with expensive supply-side reserve offers. In this work, the maximum number of multiple simultaneous contingencies is found, and infeasibilities are avoided. Nguyen et al. [81] proposed a method for optimally selecting the locations of DR along with their capacities. The objectives are maximizing available transmission capacity (ATC), minimizing expected energy not supplied (EENS), minimizing active power loss and minimizing total DR program capacity. In case of such multiple objectives that are conflicting in nature, the non-dominated sorting genetic algorithm (NSGA II) is used to obtain an optimal solution, for a given domain of possible solutions.

\section{B. Industrial and commercial Sectors Participation in DR}

Industrial loads have both the motivation and the ability to support power system operation through DR. In [72], the focus is on the steel plant and optimizing its schedule to maximize its profits from both the energy and the spinning reserve markets. In the liberalized electricity markets, controllable demand has the opportunity to participate in the real-time markets. Ruiz et al. [79] seek a way to enable aggregators to bid in markets with the help of virtual power plant (VPP) concept. VPP is composed of a large number of controllable customers, and the focus is on the aggregation of domestic and commercial customers with appliances that have thermal storage capabilities. The proposed algorithm is able to obtain the maximum load reduction over a considered control period. Papadaskalopoulos et al. [55] demonstrated the applicability of a new pool market mechanism, considering two reschedulable demand technologies with significant potential, namely electric vehicles with flexible charging capability and electric heat pump systems accompanied by heat storage for space heating.

\section{C.Markets' Uncertainty in the Presence of DR}

The uncertainty modeling in the electricity market operation in the presence of DR programs have been implemented by different methods including stochastic programming [91], robust optimization [92] and information gap decision theory (IGDT) [89]. Henriquez et al. [91] presented an optimization model to determine the optimal operation of a DR aggregator that manages a portfolio of DR programs in the wholesale electricity markets. The uncertainty of market prices and balancing requirements are represented through a set of scenarios based on historical data. The proposed model is a stochastic bi-level mathematical program that is reformulated as a mixed-integer linear program.

Mahboubi-Moghaddam et al. [92], present a new two-step iterative framework to improve the performance of energy service providers. The main problem includes reliability constraints, and price uncertainties are modeled using a robust optimization approach. It is concluded that the reliability-constrained model provides more technical and financial benefits [92]. Kazemi et al. [89] presented a combined scheduling and bidding algorithm for constructing the bidding curve of an electric utility that participated in the day-ahead energy market. The market uncertainty has been modeled using nonprobabilistic IGDT. Effects of the retail side and its risk reduction in the short-term planning were studied. The process of deriving bidding curve was presented to manage the risk of participating in the wholesale market.

\section{Centralized or Decentralized DR?}

Based on where the response decision is made, DR programs and associated technologies are categorized into centralized and decentralized control [93]. Papadaskalopoulos et al. [83] proposed a novel day-ahead pool market clearing mechanism, combining the solution optimality of centralized mechanisms and the decentralized 
demand participation structure of dynamic pricing schemes based on Lagrangian relaxation principles. The mechanism involves a bilevel iterative process, consisting of a number of maximization subproblems - expressing the market participants' price response coordinated by a global price update algorithm - expressing the market operator's effort to reach an optimal clearing solution.

System operators start to believe that DERs should be procured and as it is difficult for customers to participate directly in the electricity market, Valero et al. [76] suggest that trading in the market can be done with the help of an aggregator acting as an enrolling participant in ISO programs.

Mohsenian-rad [88] showed how time-shiftable load could submit its demand bids to the day-ahead and real-time markets to minimize its energy procurement cost. It developed a multistage stochastic optimization framework, together with several closed-form solutions, to select the demand bids considering both per-subload bidding and single bidding. The designs in this paper can help large consumers, LSEs, and utilities to exploit their time-shiftable load potentials to lower their energy costs in electricity markets.

\section{E. Cost vs. Benefit of DR in Electricity Markets}

Implementing DR in markets has positive effects on the total cost of energy and market clearing price [94]. Negash et al. [95] solved the problem of unbalance in markets caused by paying for load reductions by proposing a cost allocation method based on locational marginal price (LMP) sensitivity that accounts for the effect of congestion on the distribution of benefits between nodes with different LMPs. It also defined a fairness index to evaluate the performance of the proposed method as compared to a load-based allocation. Su et al. [77], proposes a bidding mechanism to reduce market-clearing prices and to manage the risk of going unbalanced after the closure of a day-ahead market with demand shifting of consumers who do submit price-sensitive bids [77]. In [80], two types of DR, namely reliability-based DR and price-based DR are discussed. In 2013, Gkatzikis et al. [82] investigate the interaction of end-users, the utility operator, and several aggregator entities that act as intermediaries. None of reliability-based and price-based types of DR can achieve maximum benefits. Hence, a hybrid framework with coordination between price-based and reliabilitybased DR is required to attain full benefits. Moreover, it can be concluded from the literature that accessing users' information enables the operator to exploit most of the DR benefits for itself. Thus, a non-cooperative market can be fairer.

\section{BENEFITS AND DRAWBACKS OF INDUSTRIAL AND COMMERCIAL} DR

\section{A. Industrial sector}

Some industrial loads including metals such as aluminum smelting pots, furnaces and steel, cement, freezers, refrigeration for the food industry, pumps, mills, fans, crushers have already been considered in DR programs with success. Both industrial production and support services have been considered in DR programs, thus involving equipment of the industrial process (machine drives, furnaces, pumps) and loads not directly involved in the production (ventilation, lighting, heating, cooling) [5]. DR programs foresee the participation of industrial and commercial loads to the energy and ancillary services markets and their contribution to the balancing of the fluctuation related to load and generation variations by means of load shifting, load following, and regulation.

In the industrial sector, even if most industries have already the necessary measurement, control, and communication infrastructures, DR implementation in the industrial sector requires a preliminary study involving both the facility and corporation and evaluating the benefits and risks related to industrial DR is a complex decision making process. In order to induce, in fact, the corporation to authorize the settling of the shifting or curtailment of the production in response to electricity prices in the energy or ancillary services markets, the related risks should be assessed by carrying out a time consuming and complex process. The risks are mainly related to the amount of DR flexibility that can be achieved in the facility's production schedule and on the ability of the facility to modify logistics systems and enlarge inventories. When deciding to participate in an industrial DR program, the customers can choose between self schedule DR, according to which, depending on the potential net earnings, they can select when to offer a curtailment in the market, and a form of call option according to which the customers are advised by the system operator of a curtailment alert. Another possible option is that the company stipulates a bilateral agreement with a third party that will be in charge to administer its DR capability. Industrial customers involved in a DR program have thus to face complex decisions about trade-offs related to the costs and benefits. The costs due to DR implementation are mainly related to the diminished performances and efficiency of the production processes, additional energy losses, lost equipment life, additional smart metering devices and Energy Management Systems (EMS) [5].

\section{B. Commercial sector}

Large commercial buildings with an EMS and an Internet connection have been involved in DR programs thanks to their ability to shift energy use based on a variety of load-shed and load control strategies mainly involving controllable and sheddable loads. Controllable loads mainly include Heating, ventilation, and air conditioning (HVAC) systems that can be controlled by adjusting the cooling and heating temperature setpoints by managing the thermostat settings also in accordance with the electricity price over time or market price [96].

The thermostat can generally be controlled by using a transaction based or a price based controls [97]. In the first case, the thermostat setting can be controlled by a transactive controller based on the market price while in the price-based programs consumers modify their energy consumption in response to electricity price variations. Lighting can be easily controlled by considering the interaction between the daylight and artificial light and the interactions with the users. Sheddable demands consist of some electrical equipment, such as pumps, elevators and lifts, and the equipment can be managed by adopting variable-speed drives. On-site cogeneration can also be integrated with DR actions in order to improve the earnings deriving by the DR program. Building automation systems (BAS) are generally implemented for in commercial building taking part in a DR program.

\section{Commercial and Industrial DR}

In order to understand the financial performances of industrial and large commercial customers, it is important to understand the different types of business models that can be adopted [98]. According to most of these models, revenues are earned by means of subscription fees, e.g., returns from the utility due to the endowment of the DR management software or brokerage fees deriving from a portion of the revenue charged to the utility for the supplying of the DR resource. Most of the business models have been developed considering liberalized power markets [99] and are related to market-based capacity and reserve DR.

The revenues are associated with the sales of DR services, including primary and secondary reserves [100] being the latter favored among DR providers, as it has a lower response time and is dispatched less frequently. In most cases, customers are generally endowed with an EMS enabling them to take part in DR programs even if other measures according to which customers respond 
manually are also possible. The EMS is furnished by an ISO with market interaction and allows the control of loads such as HVAC and refrigeration units, heating, lighting, ventilation, variablefrequency drive units, industrial process loads and customer-sited generation [101].

A different business model considers the utility-based capacity and reserve DR according to which a regulated utility contract with DR providers to procure operating reserve and firm capacity [98] and the prices of DR resources are agreed with the regulator and the utility. A portion of the revenues received by the DR aggregators is gained by participating load resources that are not generally under the explicit control or receive dispatch signals being their involvement based on incentives [102].

Another business model considers the provision by EMS providers of energy management systems having the target to optimize the local energy consumption considering energy process and user's requirements, but without interacting with the market. Both commercial and industrial customers take part in these types of DR programs where the revenues are obtained not only by brokerage and subscription fees, but also from asset sales related to the equipment [98].

In all the presented business models, commercial and industrial users can have economic benefits, related to electricity cost savings and incentive payments, and reliability benefits due to reduced probability of load curtailment and shortages. Other benefits offered by DR programs are related to market efficiency, by lowering wholesale market prices, avoiding congestions and reducing market power by some producers [97]. System operation and expansion benefits can be achieved thanks to DR programs in terms of ancillary market reduced prices, delayed network and generation investments [5], [103].

\section{Drawbacks of industrial and commercial DR}

Although the implementation of DR on industrial and commercial sectors has various advantages, there are some drawbacks too. The first drawback of industrial and commercial DR is related to decreasing the income of utilities. Although DR helps to decrease costs from utility viewpoint, it can reduce revenues as well. Depend on the regulatory regime in each country or region; utilities will lose a part of their profit, if a significant level of DR is implemented since the utilities are paid for generating and transmitting that are not part of DR.

Two other drawbacks of industrial and commercial DR are (i) infrastructure cost of smart metering and communication system, (ii) environmental impacts of dispatching more polluted onsite generation [104]. In Section VI, the challenges and barriers to industrial and commercial DR are discussed.

\section{CHALLENGES AND BARRIERS TO INDUSTRIAL AND COMMERCIAL DR}

The barriers of industrial and commercial DR can be divided into several aspects. It can be studied based on the market, technological, social and regulation aspects.

\section{A. Market}

- Collecting and processing data: In the transition stage from conventional power system framework to fully competitive market, DR execution has faced some barriers including limited access to the information of different parties (imperfect information), property rights are not defined completely (incomplete markets) and uncompetitive markets [11]. In terms of access to information, the potential of DR providers is not fully realized for all individual, commercial and industrial consumptions [105]. Meanwhile, collecting and processing data take costs in the market. Providing these data may not be cost-efficient for a party; hence, one party may be better informed than others [106]. One of the examples of this state is when a small commercial consumer cannot forecast its electric heating loads. For the second term, which is about property rights, the responsibility for paying the $\mathrm{CO} 2$ emission cost is not particular, and many parties should be a part of this cost. Moreover, the profits of some assets are not clear. For example, a decrease in peak load may cause profit for lots of parties, but some of them would take advantage of this reduction without any payment.

- Hidden costs and market power: For the uncompetitive market, some parties may charge prices more than their marginal cost due to the market power. The uncertainty of the market related to costs and revenues can be negotiated because some participants cannot reduce the uncertainty by risk analysis [107]. The negotiations and contract and transaction costs may put as hidden cost because parties may pay for them. They may be taken into account as barriers, especially for small parties.

- Increase the standardization: Energy and capacity, as well as DR products, are traded as a defined product and standardized according to the amount $(\mathrm{kW} / \mathrm{kWh})$ and time (week-ahead/ day-ahead) [10]. Reducing this standardization by definitions of standardized products without restriction causes an increase the DR value and system efficiency; however, increase the standardization leads to transaction costs reduction. Hence, this is a challenge that the market faces for DR [108].

\section{B. Social and customer behavior}

- Trust level among parties: The social barriers can be in associated with the power of parties. In other words, if an organization, which is responsible for implementation of DR programs, does not have enough power to install necessary technology or invest for increasing the flexibility, it may cause some barriers to both industrial and commercial DR programs. Insufficient power of decision makers may be due to the market structure and the culture of organizing a firm in a country. The behavior of customers including industrial and commercial is not definite. In fact, their behavior is supposed to be rational which means profit for these customers should be maximized. However, in reality, it may not be followed. If the information provided by the sender is not correct enough according to their behavior, the receipt's behavior will not be what sender expected [8]. The way the recipient received information from sender should be trusted. The level of trust among parties should be high enough to prevent barriers for DR. In other words, DR providers should trust sender and receive them as a reliable way, and it is important for acceptance of DR [109]. For example, DR providers prefer to interact with local and small DR buyers identified with trust rather than large energy utilities.

- Widespread adoption of DR programs: Some of the commercial and industrial customers may be identified by their values in environmental and energy conservation that promote the behavior of these customers without any consideration in DR [5]. Therefore, customers' value should be taken into account. However, it can be a barrier to DR due to the use of open and untrusted network and a huge number of physically distributed devices for these values. The consumer values may be significant for DR providers to provide comfort and convenience; therefore, the elimination of consumer's comfort is a remarkable barrier to DR [110]. Saving the customers' electric bills is not enough to encourage them to incorporate the DR programs, invest in required facilities and to compensate for their inconvenience. Therefore, for coping with the barriers related to the widespread adoption of DR programs, making a good strategy to pursue customers is essential. Since the intention of power systems is to provide electricity for consumers, DR programs are playing the opposite role. Therefore, behavior of customer should be anticipated 
as much as possible to cope with this significant barrier to DR. Lack of understanding the benefits of DR can cause less investment by different parties to expand the DR and reduce interest in development of DR technologies [9].

\section{Technological barrier}

- Sensing, computing and communication: In technological aspects, using information and communication technology (ICT) and the internet of things (IoT) is the barriers to DR. Local metering to define DR delivery, communications between DR provider and purchaser are taken into account in ICT that can be interchangeably used with IoT. The barriers in this term are mostly related to sensing, computing and communication [11]. Energy market trade from 15 minutes to 1 -hour periods requires trustworthy metering sensors at this resolution for participants of the market. Implementation of DR may need better resolution for frequency response and constraint management. Likewise, when the essential metering infrastructure does not exist, DR implementation faces some barriers [111]. Because DR programs need to have enough and adequate data and information from different parties and participants including, customers, retailers, load-serving entity (LSE), market operator, etc. to be performed correctly. Sensing at high frequency along with high reliability in a way that flexibility and extensibility should be met in an acceptable and reasonable cost is the most remarkable challenge of commercial and industrial DR implementation. This is even worse while considering the heterogeneity of sensors introduced through standards, sellers and protocols in smart grids development. A large amount of data computation with uncertainty in DR potential and DR prices can be a barrier for optimal DR. Because this uncertainty can increase the computation load price at stochastic optimization especially when decisions are constrained by time. For example, IoT embedded devices may have to be limited in computation; therefore, services will need huger compute capacity now or in the future. In computational capacity barrier, privacy and security play an important role as well. Moreover, to deliver the right compute capacity, in addition to meeting required security and privacy, acceptable cost should be taken into account. Assuming the precise data sensing and enough computational capacity, one should handle access to data. All obtained data either in wired or wireless sensors require addressing standards and protocols for data formatting and transformation.

- Technological skills: If all data could exchange by all participants in an agreed way, DR concept would run in the rapid way. However, in reality, due to some competing approaches, this interaction is in a very slow process. Moreover, since the potential domain of communication layers is widespread, making the decision for investment in which one is difficult which can be another barrier in this term. Meanwhile, there should be some technical talents for designing these technologies and assembling in a good way. Having good local support for these technologies requires experts. Therefore, another barrier to industrial and commercial DR can be technological skills. IoT systems have more complexity and diversity application; therefore, it creates challenges for training the right technical and experts to design and build IoT systems for DR running.

\section{Regulatory barriers}

- Lack of regulation for DR: Government decisions can sometimes cause barriers to DR. The effects of these policies like tax coding on market and DR operation, operational or capital costs on DRenabling technology investment can create a barrier to the efficient DR operation [112]. All regulations of electricity systems are based on the assumption that the power flow is from large-scale generators to distributed users [113]. Hence, there is no adequate regulation for demand side participants in terms of minimum bid size, gate closure time and other characteristics related to DR. In some current regulations, it is prevented to reach the market price signals to customers that cause some damages for business DR. Therefore, rules limitations for locational price differentiation in markets will avoid all customer to receive right value of DR [5].

- Various regulations in different countries: Lack of enough attention to research and development, longer regulatory periods and advantages of capital expenditure pursue the operator to expand the grid rather than expand the DR operation [10]. The regulations and policies in various countries are different. Therefore, each country should have their regulation for DR. For example, the U.S. business model has DR aggregators who sell their DR capacity to the wholesale electricity market. However, in China due to lack of existence of wholesale electricity market, grid companies make a contract with power generators, and there is no incentive for them to contract with DR aggregators because of lack of policymaking transparency [114].

\section{CONCLUSIONS}

In this paper, a comprehensive review of the recent advances in industrial and commercial DR was carried out. The potential of these sectors in providing DR was analyzed, and the impact of different technologies on reaching an effective DR participation was investigated. In addition, the business models of commercial and industrial DR were categorized, and the objective functions and constraints were presented. The role of the industrial and commercial sectors in the electricity market was discussed, and their beneficial aspects and the barriers were investigated. In future work, control and optimization algorithms for DR in both centralized and distributed forms should be investigated. In addition, since DR can be formulated as optimization problems, mathematical formulations, and hard and soft constraints should be surveyed in future work.

\section{REFERENCES}

[1] S. Mohagheghi and N. Raji, "Dynamic Demand Response: A Solution for Improved Energy Efficiency for Industrial Customers," IEEE Ind. Appl. Mag., vol. 21, no. 2, pp. 54-62, Mar. 2015.

[2] A. M. Smith and M. A. Brown, "Demand response: A carbon-neutral resource?," Energy, vol. 85, pp. 10-22, Jun. 2015

[3] S. Zhou, Z Shu, Y. Gao, H. B. Gooi, S. Chen, and K. Tan "Demand response program in Singapore's wholesale electricity market," Electr. Power Syst. Res., vol. 142, pp. 279-289, Jan. 2017.

[4] J. Aghaei and M.-I. Alizadeh, "Demand response in smart electricity grids equipped with renewable energy sources: A review," Renew. Sustain. Energy Rev., vol. 18, pp. 64-72, Feb. 2013.

[5] M. H. Shoreh, P. Siano, M. Shafie-khah, V. Loia, and J. P. S. Catalao, "A survey of industrial applications of Demand Response," Electr. Power Syst. Res., vol. 141, pp. 31-49, Dec. 2016.

[6] R. Deng, Z. Yang, M.-Y. Chow, and J. Chen, "A survey on demand response in smart grids: Mathematical models and approaches," IEEE Trans. Ind. Informat., vol. 11, no. 3, pp. 570-582, Jun. 2015.

[7] J. S. Vardakas, N. Zorba, C.V. Verikoukis, "A Survey on Demand Response Programs in Smart Grids: Pricing Methods and Optimization Algorithms," IEEE Communication Surveys \& Tutorials, vol. 17, no. 1, pp. 152-178, 2015.

[8] S. Nolan and M. O'Malley, "Challenges and barriers to demand response deployment and evaluation," Appl. Energy, vol. 152, pp. 1-10, Aug. 2015.

[9] N. O'Connell, P. Pinson, H. Madsen, and M. O'Malley, "Benefits and challenges of electrical demand response: A critical review," Renew. Sustain. Energy Rev., vol. 39, pp. 686-699, Nov. 2014.

[10] M. Vallés, J. Reneses, R. Cossent, and P. Frías, "Regulatory and market barriers to the realization of demand response in electricity distribution networks: A European perspective," Electr. Power Syst. Res., vol. 140, pp. 689-698, Nov. 2016

[11] N. Good, K. A. Ellis, and P. Mancarella, "Review and classification of barriers and enablers of demand response in the smart grid," Renew. Sustain. Energy Rev., vol. 72, pp. 57-72, May 2017.

[12] P. Wan, M. D. Lemmon, "Optimal power flow in microgrids using eventtriggered optimization," in Proc. American Control Conference, Baltimore, pp. 2521-2526, 2010

[13] R. Yu, W. Zhong, S. Xie, C. Yuen, S. Gjessing, Y. Zhang, "Balancing Power Demand Through EV Mobility in Vehicle-to-Grid Mobile Energy Networks," IEEE Trans. Industrial Informatics, vol. 12, no. 1, pp. 79-90, Feb. 2016.

[14] A. Brooks, E. Lu, D. Reicher, C. Spirakis, and B. Weihl, "Demand dispatch," IEEE Power Energy Mag., vol. 8, no. 3, pp. 20-29, May/Jun. 2010. 
[15] G. Graditi, M. L. Di Silvestre, R. Gallea, and E. Riva Sanseverino, "Heuristicbased shiftable loads optimal management in smart microgrids," IEEE Trans. Ind. Informat., vol. 11, no. 1, pp. 271-280, Feb. 2015.

[16] Y. Liu, C. Yuen, S. Huang, N. Ul Hassan, X. Wang, and S. Xie, "Peak-toaverage ratio constrained demand-side management with consumer's preference in residential smart grid," IEEE J. Sel. Topics Signal Process., vol. 8, no. 6, pp. 1084-1097, Dec. 2014.

[17] S.Y. Derakhshandeh, A.S. Masoum, S. Deilami, M.A.S. Masoum, M. E. H Golshan, "Coordination of Generation Scheduling with PEVs Charging in Industrial Microgrids," IEEE Transactions on Power Systems, Vol.28, No.3, pp.3451-4361, 2013.

[18] EPIA Team, "Solar Europe industry initiative implementation plan 20102012," May 2010, [Online]. Available: http://ec.europa.eu/energy/technology/initiatives/doc/pv_implementation plan final.pdf.

[19] $\bar{H}$. Be-tran, E. c, N. Aparicio, P. Rodríguez, "Daily solar energy estimation for minimizing energy storage requirements in PV power plants," IEEE Trans. Sustainable Energy, 2012 .

[20] M. K. C. Marwali, M. Haili, S. M. Shahidehpour, K.H. Abdul-Rahman, "Short term generation scheduling in photovoltaic-utility grid with battery storage," IEEE Trans. Power Syst., vol. 13, no. 3, pp. 1057-1062, 1998.

[21] Y. M. Ding, S. H. Hong, X. H. Li, "A Demand Response Energy Management Scheme for Industrial Facilities in Smart Grid," IEEE Trans. Industrial Informatics, vol. 10, no. 4, pp. 2257-2269, Nov. 2014.

[22] S. Mohagheghi, N. Raji, "Intelligent demand response scheme for energy management of industrial systems," in Proc. IEEE IAS Ann. Meet., Las Vegas, NV, USA, Oct. 7-11, 2012, pp. 1-9.

[23] Y. Yan, Y. Qian, H. Sharif, D. Tipper, "A survey on cyber security for smart grid communications," IEEE Commun. Surveys Tuts., vol. 14, no. 4, pp. 998 1010,2012

[24] F. Starfelt, J. Yan, "Case study of energy systems with gas turbine cogeneration technology for an eco-industrial park," International Journal of Energy Research, vol. 32, no. 12, pp. 1128-1135, 2008.

[25] S. Chowdhury, S.P. Chowdhury, P. Crossley, Microgrids and Active Distribution Networks, IET, London, pp. 15-16, 2009.

[26] N. Wägar, "Wind-diesel or wind-gas, cases and possibilities by Wärtsilä," in Proc. International Wind-Diesel Workshop, 2008. [Online]. Available: http://apps1.eere.energy.gov/ tribalenergy/pdfs/wind akco10.pdf.

[27] A. Grein, M. Pehnt, "Load management for refrigeration systems: Potentials and barriers," Energy Policy, vol. 39, no. 9, pp. 5598-5608, Sep. 2011.

[28] M. E. Khodayar, L. Wu, M. Shahidehpour, "Hourly coordination of electric vehicle operation and volatile wind power generation in SCUC" IEEE Trans. Smart Grid, vol. PP, no. 99, pp. 1-9, 2012.

[29] M. Zeng, S. Leng, S. Maharjan, S. Gjessing, J. He, "An incentivized auction based group-selling approach for demand response management in V2G systems," IEEE Trans. Industrial Informatics, vol. 11, no. 6, pp. 1554-1563, 2015.

[30] H. Liu, H. Ning, Y. Zhang, Q. Xiong, and L. T. Yang, "Role-dependent privacy preservation for secure V2G networks in the smart grid," IEEE Trans. Inf. Forensics Security, vol. 9, no. 12, pp. 208-220, Dec. 2014

[31] F. Xia, L. T. Yang, L. Wang, and A. Vinel, "Internet of things," Int. J. Commun. Syst., vol. 25, no. 9, p. 1101, 2012

[32] Z. Fu, X. Sun, Q. Liu, L. Zhou, and J. Shu, "Achieving efficient cloud search services: Multi-keyword ranked search over encrypted cloud data supporting parallel computing," IEICE Trans. Commun., vol. 98, pp. 190-200, Jan. 2015.

[33] C. Chen and S. Duan, "Optimal integration of plug-in hybrid electric vehicles in microgrids," IEEE Trans. Ind. Informat., vol. 10, no. 3, pp. 1917-1926, Aug. 2014

[34] J. Zhao, F. Wen, Z. Y. Dong, Y. Xue, and K. P. Wong, "Optimal dispatch of electric vehicles and wind power using enhanced particle swarm optimization," IEEE Trans. Ind. Informat., vol. 8, no. 4, pp. 889-899, Nov. 2012.

[35] H. Liu, Z. Hu, Y. Song, and J. Lin, "Decentralized vehicle-to-grid control for primary frequency regulation considering charging demands," IEEE Trans. Power Syst., vol. 28, no. 3, pp. 3480-3489, Aug. 2013

[36] H. Liang, B. J. Choi, W. Zhuang, and X. Shen, "Optimizing the energy delivery via V2G systems based on stochastic inventory theory," IEEE Trans. Smart Grid, vol. 4, no. 4, pp. 2230-2243, Dec. 2013.

[37] J. J. Escudero-Garzás, A. García-Armada, and G. Seco-Granados, "Fair design of plug-in electric vehicles aggregator for V2G regulation," IEEE Trans. Veh. Technol., vol. 61, no. 8, pp. 3406-3419, Oct. 2012.

[38] Z. Darabi and M. Ferdowsi, "An event-based simulation framework to examine the response of power grid to the charging demand of plugin hybrid electric vehicles," IEEE Trans. Ind. Informat., vol. 10, no. 1, pp. 313-322, Feb. 2014

[39] P. Yi, T. Zhu, B. Jiang, B. Wang, and D. Towsley, "An energy transmission and distribution network using electric vehicles," in Proc. IEEE Int. Conf. Commun. (ICC), 2012, pp. 3335-3339.

[40] P. Yi, T. Zhu, G. Lin, and Q. Zhang, "Routing renewable energy using electric vehicles in mobile electrical grid," in Proc. IEEE 10th Int. Conf. Mobile AdHoc Sensor Syst. (MASS), 2013, pp. 19-27.

[41] M. Doostizadeh and H. Ghasemi, "A day-ahead electricity pricing model based on smart metering and demand-side management," Energy, vol. 46, no. 1, pp. 221-230, Oct. 2012

[42] H. P. Chao, "Price-responsive demand management for a smart grid world," Electricity J., vol. 23, no. 1, pp. 7-20, Jan.-Feb. 2010.

[43] M. Choobineh, S. Mohagheghi, "Optimal Energy Management in an Industrial Plant Using On-Site Generation and Demand Scheduling," IEEE Trans. Industry Applications, vol. 52, no. 3, pp. 1945-1952, May 2016.
[44] K. Sakurama, M. Miura, "Communication-Based Decentralized Demand Response for Smart Microgrids," IEEE Trans. Industrial Informatics, vol. 64, no. 6 , pp. 5192-5202, June 2017.

[45] W. Shi, X. Xie, C.C. Chu, R. Gadh, "Distributed optimal energy management in microgrids," IEEE Trans. Smart Grid, Vol. 6, pp.1137-1146, May 2015.

[46] C.-H. Lo, N. Ansari, "The progressive smart grid system from both power and communications aspects," IEEE Commun. Surveys Tuts., vol. 14, no. 3, pp. 799-821, 2012

[47] V. Cagri Gungor, D. Sahin, T. Kocak, S. Ergut, C. Buccella, C. Cecati, G. P. Hancke, "A Survey on Smart Grid Potential Applications and Communication Requirements," IEEE Trans. Industrial Informatics, vol. 9, no. 1, pp. 28-42, Feb. 2013.

[48] G. T. Costanzo, G. Zhu, M. F. Anjos, and G. Savard, "A system architecture for autonomous demand side load management in smart buildings," IEEE Trans. Smart Grid, vol. 3, no. 4, pp. 2157-2165, Dec. 2012.

[49] X. Fang, S. Misra, G. Xue, and D. Yang, "Managing smart grid information in the cloud: Opportunities, model, applications," IEEE Netw., vol. 26, no. 4, pp. 32-38, Jul./Aug. 2012.

[50] K. Moslehi and R. Kumar, "A reliability perspective of the smart grid," IEEE Trans. Smart Grid, vol. 1, no. 1, pp. 57-64, Jun. 2010.

[51] S. Lu, S. Repo, D.D. Giustina, F.A.C. Figuerola, A. Löf, M. Pikkarainen, "Real-time low voltage network monitoring- ICT architecture and field test experience," IEEE Trans. Smart Grid, Vol. 6, No. 4, pp.2002-2012, 2015.

[52] M. Wissner, "The smart grid-A saucerful of secrets?" Appl. Energy, vol. 88, no. 7, pp. 2509-2518, Jul. 2011

[53] X. Fang, Q. Hu, F. Li, B. Wang, and Y. Li, "Coupon-based demand response considering wind power uncertainty: a strategic bidding model for load serving entities," IEEE Trans. Power Syst., vol. 31, no. 2, pp. 1025-1037, Mar. 2016.

[54] Q. Shi, F. Li, Q. Hu, and Z. Wang, "Dynamic demand control for system frequency regulation: concept review, algorithm comparison, and future vision," Electr. Power Syst. Res., vol. 154, pp. 75-87, Jan 2018.

[55] D. Papdaskalopoulos G. Strbac, P. Mancarella, M. Aunedi, and V. Stanojevic, "Decentralized Participation of Flexible Demand in Electricity Markets - Part II: Application with Electric Vehicles and Heat Pump Systems," IEEE Trans. Power Syst., vol. 28 , no. 4, pp. 3667-3674, Nov 2013.

[56] L. Yao, W. H. Lim and T. S. Tsai, "A real-time charging scheme for demand response in electric vehicle parking station," IEEE Trans. Smart Grid, vol. 8, no. 1, pp. 52-62, Jan. 2017.

[57] S. Han, and K. Sezaki, "Development of an optimal vehicleto-grid aggregator for frequency regulation," IEEE Trans. Smart Grid, vol. 1, no. 1, pp. 65-72, Jun. 2010.

[58] W. Su and M.-Y. Chow, "Computational intelligence-based energy management for a large-scale PHEV/PEV enabled municipal parking deck," Appl. Energy, vol. 96, pp. 171-182, Aug. 2012.

[59] C. Jin, J. Tang, and P. Ghosh, "Optimizing electric vehicle charging: A customer's perspective," IEEE Trans. Veh. Technol., vol. 62, no. 7, pp. 29192927, Sep. 2013.

[60] C. Jin, J. Tang, and P. Ghosh, "Optimizing electric vehicle charging with energy storage in the electricity market," IEEE Trans. Smart Grid, vol. 4, no. 1, pp. 311-320, Mar. 2013.

[61] M. Ansari, A. T. Al-Awami, E. Sortomme, and M. A. Abido, "Coordinated bidding of ancillary services for vehicle-to-grid using fuzzy optimization," IEEE Trans. Smart Grid, vol. 6, no. 1, pp. 261-270, Jan. 2015.

[62] M. S. Kuran et al., "A smart parking lot management system for scheduling the recharging of electric vehicles," IEEE Trans. Smart Grid, vol. 6, no. 6, pp. 2942-2953, Nov. 2015.

[63] B. Skugor and J. Deur, "Dynamic programming-based optimisation of charging an electric vehicle fleet system represented by an aggregate battery model," Energy, vol. 92, pp. 456-465, Dec. 2015.

[64] M. Shafie-Khah et al., "Optimal behavior of electric vehicle parking lots as demand response aggregation agents," IEEE Trans. Smart Grid, vol. 7, no. 6, pp. 2654-2665, Nov. 2016.

[65] J. A. Crabb, N. Murdoch, and J. N. Penman, "A simplified thermal response model," Building Serv. Eng. Res. Technol., vol. 8, no. 1, pp. 13-19, Feb. 1987.

[66] D. Papadaskalopoulos, P. Mancarella, and G. Strbac, "Decentralized, agentmediated participation of flexible thermal loads in electricity markets," in Proc. Intell. Syst. Appl. Power Syst. Conf., Crete, Greece, 2011.

[67] L. D. Danny Harvey, A Handbook on low-Energy Buildings and DistrictEnergy Systems. London, U.K.: Earthscan, 2006.

[68] X. Zhang and G. Hug, "Bidding strategy in energy and spinning reserve markets for aluminum smelters' demand response," 2015 IEEE Power \& Energy Society Innovative Smart Grid Technologies Conference (ISGT), Washington, DC, 2015, pp. 1-5.

[69] X. Zhang and G. Hug, "Optimal regulation provision by aluminum smelters," 2014 IEEE PES General Meeting, National Harbor, MD, 2014, pp. 1-5.

[70] D. Todd, M. Caufield, B. Helms, A. P. Generating, I. M. Starke, B. Kirby, and J. Kueck, "Providing reliability services through demand response: A preliminary evaluation of the demand response capabilities of Alcoa Inc," $O R N L / T M$, vol. 233, 2008.

[71] P M. Castro, L Sun, and L Hajunkoski, "Resource-task network formulations for industrial demand side management of a steel plant," Industrial \& Engineering Chemistr Research, vol. 52, no. 36, pp. 13046-13058,2013.

[72] X. Zhang, G. Hug, J. Z. Kolter, and I. Harjunkoski, "Industrial demand response by steel plants with spinning reserve provision," in 47th North American Power Symposium, 2015. 
[73] X. Zhao et al., "A model of Demand Response scheduling for cement plant," 2014 IEEE International Conference on Systems, Man, and Cybernetics (SMC), San Diego, CA, 2014, pp. 3042-3047.

[74] L. Merkert, et al. Scheduling and energy-Industrial challenges and opportunities. Computers \& Chemical Engineering, vol. 72, pp. 183-198, 2015.

[75] E. J. Paulson, "Demand response as ancillary service in the PJM RTO," IEEE Power Engineering Society General Meeting, June 2005

[76] S. Valero, M. Ortiz, C. Senabre, C. Alvarez, F. J. G. Franco and A. Gabaldon, "Methods for customer and demand response poilicies selection in new electricity markets," IET Generation Transmission and Distribution, vol. 1, no. 1, pp. 104-110, Jan. 2007.

[77] Chua-Liang Su and Daniel Kirschen, "Quantifying the effect of demand response on electricity markets," IEEE Trans. on Power Syst., vol. 24, no. 3, pp. 1199-1207, Aug. 2009.

[78] E. Shayesteh, M. Parsa Moghaddam, S. Taherynejhad and M. K. Sheikh- ELEslami "Congestion management using demand response programs in power market," in Proc. of IEEE Power and Energy Society General Meeting Conversion and Delivery of Electrical Energy in the 21 st Century, 2008, pp. 18.

[79] N. Ruiz, I. Cobelo and J. Oyarzabal, "A direct load control model for virtual power plant management," IEEE Trans. on Power Syst., vol. 24, no. 2, pp. 959966, May 2009.

[80] D. T. Nguyen, "Demand Response for Domestic and Small Business Consumers: A New Challenge," in Proc. of IEEE T\&D Conference and Exposition, 2010, pp. 1-7.

[81] T. T. Nguyen and A. Yousefi, "Multi-objective demand response allocation in restructured energy market," in Proc. of IEEE Innovative Smart Grid Technologies (ISGT), 2011, pp. 1-8.

[82] L. Gkatzikis, I. Koutsopoulos, T. Salonidis, "The role of aggregators in smart grid demand response markets," IEEE Journal on Selected Areas in Communications, vol. 31, no. 7, July 2013.

[83] D. Papdaskalopoulos and G. Strbac, "Decentralized Participation of Flexible Demand in Electricity Markets - Part I: Market Mechanism," IEEE Trans. Power Syst., vol. 28, no. 4, pp. 3658-3666, Nov 2013.

[84] M. Parvania, M. Fotuhi-Firuzabad, M. Shahidehpour, "Optimal demand response aggregation in wholesale electricity markets," IEEE Trans. On Smart Grid, vol. 4, no. 4, Dec. 2013

[85] P. R. Thimmapuram, J. Kim, "Consumers' price elasticity of demand modeling with economic effects on electricity markets using an agent-based model," IEEE Trans. On Smart Grid, vol. 4, no. 1, pp. 390-397, March 2013.

[86] J. Aghaei and M.-I. Alizadeh,"Robust $\mathrm{n}-\mathrm{k}$ contingency constrained unit commitment with ancillary service demand response program," IET Generation, Transmission \& Distribution, vol.8, no.12, pp.1928-1936, 2014.

[87] M. Parvania, M. Fotuhi-Firuzabad, and M. Shahidehpour, "ISO's Optimal Strategies for Scheduling the Hourly Demand Response in Day-Ahead Markets," IEEE Trans. Power Syst., vol. 29, pp. 2636-2645, Nov. 2014.

[88] H. Mohsenian-Rad, "Optimal Demand Bidding for Time-Shiftable Loads," IEEE Trans. on Power Systems, vol. 6, no. 2, March 2015.A.I.

[89] M. Kazemi, B. Mohammadi-Ivatloo, and M. Ehsan, "Risk-Constrained Strategic Bidding of GenCos Considering Demand Response," IEEE Trans. Power Syst., vol. 30, no. 1, pp. 376-384, Jan. 2015.

[90] R. Henriquez, G. Wenzel, D. E. Olivares, M. Negrete-Pincetic, "Participation of demand response aggregators in electricity markets: optimal portfolio management," IEEE Trans. On Smart Grid, May 2017.

[91] M. Behrangrad, H. Sugihara, and T. Funaki, "Analyzing the system effects of optimal demand response utilization for reserve procurement and peak clipping," in Power and Energy Society General Meeting, 2010 IEEE, Jul. 2010, pp. 1-7.

[92] M. Song, M. Amelin, "Purchase bidding strategy for a retailer with flexible demands in day-ahead electricity market," IEEE Trans. Power Syst., vol. 32, no. 3, pp. 18339-1850, May 2017.

[93] S. Lu, N. Samaan, R. Diao, M. Elizondo, C. Jin, E. Mayhorn, Y. Zhang and H. Kirkham, "Centralized and Decentralized Control for Demand Response," in Proceedings of 2011 IEEE PES Conference on Innovative Smart Grid Technologies (ISGT), 2011.

[94] T. Samad, S. Kiliccote, "Smart grid technologies and applications for the industrial sector," Comput. Chem. Eng., vol.47, pp. 76-84, Dec. 2012.

[95] Negash, T.W. Haring, and D.S. Kirschen, "Allocating the Cost of Demand Response Compensation in Wholesale Energy Markets," IEEE Trans. Power Syst., vol. 30, no. 3, pp. 1528-1535, May 2015 .

[96] S Wang, X Xue, C Yan, Building power demand response methods toward smart grid, HVAC\&R Research 20 (6), 665-687.

[97] Siano Pierluigi, Sarno Debora, 2016. Assessing the benefits of residential demand response in a real time distribution energy market. Applied Energy, vol. 161, p. 533-551,

[98] Scott P. Burger, Max Luke, Business models for distributed energy resources: A review and empirical analysis, Energy Policy, Vol. 109, 2017, pp. 230-248.

[99] Behrangrad, M., 2015. A review of demand side management business models in the electricity market. Renew. Sustain. Energy Rev. 47, 270-283.

[100] Dehghanpour, K., Afsharnia, S., 2015. Electrical demand side contribution to frequency control in power systems: a review on technical aspects. Renew. Sustain. Energy Rev. 41, 1267-1276.
[101] Hansen, J., Knudsen, J., Annaswamy, A., 2014. Demand Response in Smart Grids: Participants, Challenges, and a Taxonomy, In: IEEE Proceedings of the 53rd Annual Conference on Decision and Control (CDC). IEEE, Los Angeles, CA, pp. 4045-4052.

[102] Mahmoudi Nadali, Heydarian-Forushani Ehsan, Shafie-khah Miadreza, Saha Tapan K., Golshan M.E.H., Siano Pierluigi (2017). A bottom-up approach for demand response aggregators' participation in electricity markets. Electr. Power Syst. Res., vol. 143, p. 121-129.

[103] European Commission DG Energy, Impact Assessment Study on Downstream Flexibility, Price Flexibility, Demand Response \& Smart Metering, Final Report, Request Number: Ener/B3/2015-641, July 2016.

[104] Shea, Ryan. "Renewable Energy Roadmap for the Island Nation of Mauritius." Fullbright US Research Student Program Report (2017).

[105] M. A. Brown, "Market failures and barriers as a basis for clean energy policies," Energy Policy, vol. 29, no. 14, pp. 1197-1207, Nov. 2001.

[106] P. Thollander, J. Palm, and P. Rohdin, "Categorizing Barriers to Energy Efficiency - an Interdisciplinary Perspective," 2010

[107] T. W. Haring, D. S. Kirschen, and G. Andersson, "Incentive Compatible Imbalance Settlement," IEEE Trans. Power Syst., vol. 30, no. 6, pp. 3338 3346, Nov. 2015

[108] E. McKenna, I. Richardson, and M. Thomson, "Smart meter data: Balancing consumer privacy concerns with legitimate applications," Energy Policy, vol. 41, pp. 807-814, Feb. 2012

[109] A. Losi, P. Mancarella, and A. Vicino, Integration of Demand Response into the Electricity Chain: Challenges, Opportunities and Smart Grid Solutions. Hoboken: Wiley-ISTE [Imprint]; John Wiley \& Sons, Incorporated, 2015.

[110] S. J. Darby and E. McKenna, "Social implications of residential demand response in cool temperate climates," Energy Policy, vol. 49, pp. 759-769, Oct. 2012.

[111]B. Cui, S. Wang, and X. Xue, "Effects and Performance of a Demand Response Strategy for Active and Passive Building Cold Storage," Energy Procedia, vol. 61, pp. 564-567, Jan. 2014.

[112] P. V. Dievel, K. D. Vos, and R. Belmans, "Demand response in electricity distribution grids: Regulatory framework and barriers," in 11th Int. Conf. on the European Energy Market (EEM14), 2014, pp. 1-5.

[113] D. Xenias, C. J. Axon, L. Whitmarsh, P. M. Connor, N. Balta-Ozkan, and A. Spence, "UK smart grid development: An expert assessment of the benefits, pitfalls and functions," Renew. Energy, vol. 81, pp. 89-102, Sep. 2015.

[114] C.-J. Yang, "Opportunities and barriers to demand response in China," Resour. Conserv. Recycl., vol. 121, pp. 51-55, Jun. 2017.

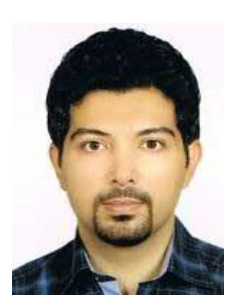

Miadreza Shafie-khah (M'13-SM'17) received the M.Sc. and $\mathrm{Ph} . \mathrm{D}$. degrees in electrical engineering from Tarbiat Modares University, Tehran, Iran, in 2008 and 2012, respectively. He received his first postdoc from the University of Beira Interior (UBI), Covilha, Portugal in 2015. $\mathrm{He}$ received his second postdoc from the University of Salerno, Salerno, Italy in 2016. Currently, he is an Assistant Professor at the University of Vaasa, Vaasa, Finland. He was considered one of the Outstanding Reviewers of the IEEE TRANSACTIONS ON SUSTAINABLE ENERGY, in 2014 and 2017, one of the Best Reviewers of the IEEE TRANSACTIONS ON SMART GRID, in 2016 and 2017, and one of the Outstanding Reviewers of the IEEE TRANSACTIONS ON POWER SYSTEMS, in 2017 and 2018. His research interests include power market simulation, market power monitoring, power system optimization, demand response, electric vehicles, price forecasting and smart grids.

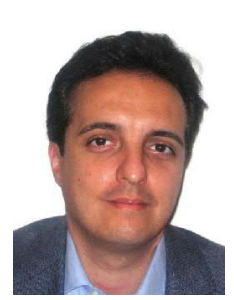

Pierluigi Siano (M'09-SM'14) received the M.Sc. degree in electronic engineering and the Ph.D. degree in information and electrical engineering from the University of Salerno, Salerno, Italy, in 2001 and 2006, respectively. He is an Associate Professor (with accreditation for Full Professor) of electrical energy engineering with the Department of Industrial Engineering University of Salerno. He has coauthored more than 300 papers including more than 150 international journal papers. His research interests include the integration of distributed energy resources in smart distribution systems and planning and management of power systems. Dr. Siano is the Chair of the Technical Committee on Smart Grids and a member of the Technical Committee on Renewable Energy Systems of the IEEE Industrial Electronics Society. He is an Editor of Intelligent Industrial Systems (Springer), an Associate Editor of the IEEE TRANSACTIONS ON INDUSTRIAL INFORMATICS, and a member of the Editorial Board of more than 30 International Journals. 


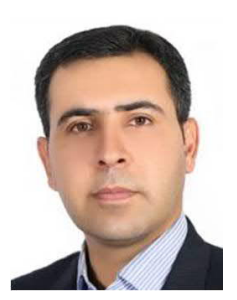

Jamshid Aghaei (M'12-SM'15) received the B.Sc. degree in electrical engineering from the Power and Water Institute of Technology, Tehran, Iran, in 2003, and the M.Sc. and Ph.D. degrees from the Iran University of Science and Technology, Tehran, in 2005 and 2009, respectively. He is currently an Associate Professor at the Shiraz University of Technology, Shiraz, Iran, and also a Research Fellow at the Norwegian University of Science and Technology, Trondheim, Norway. His research interests include renewable energy systems, smart grids, electricity markets, and power system operation, optimization, and planning. Dr. Aghaei is a Member of the Iranian Association of Electrical and Electronic Engineers and a Guest Editor of the IEEE TRANSACTIONS ON INDUSTRIAL INFORMATICS.

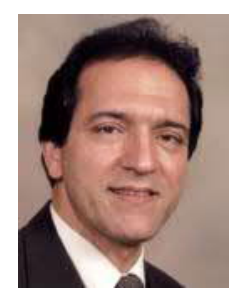

Mohammad A. S. Masoum (S'88-M'91-SM'05) received his B.S., M.S. and Ph.D. degrees from the University of Colorado, USA in 1983, 1985 and 1991, respectively. He was an Associate Professor with the Iran University of Science and Technology, Tehran, Iran from 1993 to 2003 and a Professor with Curtin University, Perth, Australia from 2004 to 2018. $\mathrm{He}$ is currently an Associate Professor with the Department of Engineering, Utah Valley University, Orem, Utah, USA. Dr. Masoum has published over 320 papers including over 130 journal articles. He has co-authored "Power Quality in Power Systems and Electrical Machines" (Elsevier, 2008 and 2015) and "Power Conversion of Renewable Energy Systems" (Springer, 2011 and 2012). Dr. Masoum is the past Editor-In-Chief of the American Journal of Engineering \& Science (2012-2014) and a past Editor of the Australian Electrical \& Electronics Engineering International Journal (2012-2018). He is currently an Editor of the IEEE TRANSACTIONS ON SMART GRID and the IEEE POWER ENGINEERING LETTERS, and a Guest Editor of the IEEE TRANSACTIONS ON INDUSTRIAL INFORMATICS and the IET Renewable Power Generation.

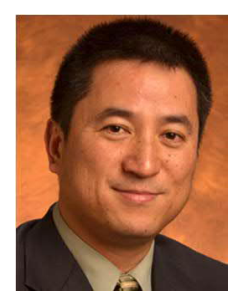

Fangxing Li (S'98-M'01-SM'05-F'17), also known as Fran $\mathrm{Li}$, received the B.S.E.E. and M.S.E.E. degrees from Southeast University, Nanjing, China, in 1994 and 1997, respectively, and the Ph.D. degree from Virginia Tech, Blacksburg, VA, USA, in 2001. Currently, he is the James W. McConnell Professor in electrical engineering and the Campus Director of CURENT at the University of Tennessee, Knoxville, TN, USA. His current research interests include renewable energy integration, distributed generation, energy markets, power system computing, reactive power and voltage stability, and measurement-based technology. Prof. Li is presently serving as the Vice Chair of IEEE PES PSOPE Committee, an Editor of the IEEE TRANSACTIONS ON POWER Systems, an Editor of the IEEE TRANSACTIONS ON Sustainable ENERGY, an Editor of IEEE PES LETTERS, and a Guest Editor of the IEEE TRANSACTIONS ON INDUSTRIAL INFORMATICS.

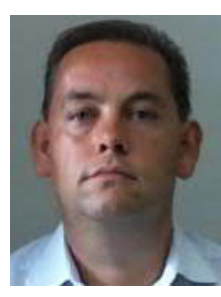

João P. S. Catalão (M'04-SM'12) received the M.Sc. degree from the Instituto Superior Técnico (IST), Lisbon, Portugal, in 2003, and the Ph.D. degree and Habilitation for Full Professor ("Agregação") from the University of Beira Interior (UBI), Covilha, Portugal, in 2007 and 2013, respectively.

Currently, he is a Professor at the Faculty of Engineering of the University of Porto (FEUP), Porto, Portugal, and Research Coordinator at INESC TEC. He was also appointed as Visiting Professor by North China Electric Power University, Beijing, China. He was the Primary Coordinator of the EU-funded FP7 project SiNGULAR ("Smart and Sustainable Insular Electricity Grids Under Large-Scale Renewable Integration"), a 5.2-million-euro project involving 11 industry partners. He has authored or coauthored more than 700 publications, including 275 journal papers (more than 80 IEEE Transactions/Journal papers), 372 conference proceedings papers, 5 books, 35 book chapters, and 14 technical reports, with an $h$-index of 47, an $i 10$-index of 197 , and over 8500 citations (according to Google Scholar), having supervised more than 70 post-docs, Ph.D. and M.Sc. students. He is the Editor of the books entitled "Electric Power Systems: Advanced Forecasting Techniques and Optimal Generation Scheduling" and "Smart and Sustainable Power Systems: Operations, Planning and Economics of Insular Electricity Grids" (Boca Raton, FL, USA: CRC Press, 2012 and 2015, respectively). His research interests include power system operations and planning, hydro and thermal scheduling, wind and price forecasting, distributed renewable generation, demand response and smart grids.

Prof. Catalão is an Editor of the IEEE TRANSACTIONS ON SMART GRID, an Editor of the IEEE TRANSACTIONS ON POWER SYSTEMS, an Associate Editor of the IEEE TRANSACTIONS ON INDUSTRIAL INFORMATICS. From 2011 till 2018 (seven years) he was an Editor of the IEEE TRANSACTIONS ON SUSTAINABLE ENERGY and an Associate Editor of the IET Renewable Power Generation. He was also a Subject Editor of the IET Renewable Power Generation. He was the Guest Editor-in-Chief for the Special Section on "Real-Time Demand Response" of the IEEE TRANSACTIONS ON SMART GRID, published in December 2012, the Guest Editor-inChief for the Special Section on "Reserve and Flexibility for Handling Variability and Uncertainty of Renewable Generation" of the IEEE TRANSACTIONS ON SUSTAINABLE ENERGY, published in April 2016, the Corresponding Guest Editor for the Special Section on "Industrial and Commercial Demand Response" of the IEEE TRANSACTIONS ON INDUSTRIAL INFORMATICS, published in November 2018, and the Lead Guest Editor for the Special Issue on "Demand Side Management and Market Design for Renewable Energy Support and Integration" of the IET Renewable Power Generation, to be published in May 2019. He was the recipient of the 2011 Scientific Merit Award UBI-FE/Santander Universities, the 2012 Scientific Award UTL/Santander Totta, the 2016 and 2017 FEUP Diplomas of Scientific Recognition, the 2017 Best INESC-ID Researcher Award, and the 2018 Scientific Award ULisboa/Santander Universities, in addition to an Honorable Mention in the 2017 Scientific Award ULisboa/Santander Universities. Moreover, he has won 4 Best Paper Awards at IEEE Conferences. 